\title{
Discursos médicos em construção: um estudo com residentes em Obstetrícia/Ginecologia do Instituto Fernandes Figueira/Fiocruz
}

PALAVRAS-CHAVE

- Internato e residência

- Obstetrícia

- Ginecologia

- Saúde da mulher

\section{KEY WORDS}

- Internship and residency

- Obstetrics

- Gynecology

- Women's Health

Construction of medical discourse: an

institutional case study with

Obstetrics/Gynecology residents at the

Fernandes Figueira Institute, Oswaldo Cruz

Foundation

\author{
Ana Cristina Bohrer Gilbert ${ }^{\mathrm{I}}$ \\ Maria Helena Cabral de Almeida Cardoso ${ }^{\mathrm{I}}$ \\ Susana Maciel Wuillaume ${ }^{\mathrm{I}}$ \\ Monica de Paula JungII
}

\begin{abstract}
R E S U M O
Este estudo discute a construção do discurso especializado, a partir do verbalizado por médicos após dois anos de residência médica em Obstetrícia/Ginecologia no Instituto Fernandes Figueira, Fundação Oswaldo Cruz. A pesquisa foi operacionalizada em duas etapas: observação participante de reuniões clínicas da Obstetrícia e da Ginecologia e construção de fontes orais. Foi realizada análise semiótica das notas de campo e do material transcrito das entrevistas. Os resultados giram em torno de dois eixos: a caracterização do perfil do médico obstetra/ginecologista e a convivência com o normal e o estranho no contato com as pacientes, como integrantes da construção do discurso especializado, no ambiente escolhido para a pesquisa. Conclui-se que a residência conduz ao discurso especializado, escudado, principalmente, na utilização de exames complementares, como os que fornecem imagens, visto que tais exames são percebidos como revelando objetivamente o corpo real. Tal fato infunde segurança nos residentes, mas, por outro lado, afasta-os da atenção à escuta da história da paciente e da composição da narrativa médica, fragmentando o processo de exercício da semiologia clínica.
\end{abstract}

\section{A B S T R A C T}

This study discusses the construction of a specialized discourse, based on the experience of Ob-Gyn medical residents at the Fernandes Figueira Institute, Oswaldo Cruz Foundation, Rio de Janeiro, Brazil. The research consisted of two steps: participant observation in Obstetrics and Gynecology meetings, and the construction of oral sources. The methodology included a semiotic analysis of field notes and interviews. The results focus on two key aspects: characterization of the profile of obstetricians/gynecologists and contact with normalcy and strangeness with patients, as part of the construction of the specialized discourse within the setting chosen for the research. The study concludes that Ob-Gyn residency leads to a specialized discourse, backed mainly by the use of complementary tests such as imaging, since such tests are perceived as objectively revealing the real body. This fact gives residents confidence, but it can also distract them from listening to the patient's history and constructing the clinical narrative, thus fragmenting the exercise of clinical semiology.

\footnotetext{
${ }^{I}$ Fundação Oswaldo Cruz, Rio de Janeiro, Brasil.

II Instituto Estadual de Diabetes e Endocrinologia Luiz Capriglione, Rio de Janeiro, Brasil; Fundação Oswaldo Cruz, Rio de Janeiro, Brasil.
} 


\section{INTRODUÇÃO}

A Obstetrícia e a Ginecologia existem como especialidades diferentes desde $1911^{1}$. Integram o quadro das chamadas áreas básicas na medicina, sendo consideradas essencialmente cirúrgicas. Apesar de tratadas como separadas, envolvendo características e aptidões diferentes daqueles que as praticam, estão atreladas na residência, embora os programas sejam elaborados e cumpridos de forma independente.

Em seus primórdios, a Obstetrícia era mais ligada à experiência do médico e à sua prática, enquanto a Ginecologia, por ser essencialmente cirúrgica, acompanhou as descobertas científicas que impulsionaram a cirurgia, como o advento da anestesia e da assepsia no século 19. Antes disso, por sua manualidade e aspecto sangrento, a cirurgia era uma atividade desvalorizada e também seu praticante, que deveria possuir habilidade, destreza e características que permitissem suportar os gritos do paciente decorrentes da ausência de anestesia ${ }^{2}$.

A partir do século 19, muitos obstetras tornaram-se ginecologistas por seu maior conhecimento do corpo da mulher e pelo fato de a Ginecologia começar a se apresentar como atividade mais rentável devido ao ganho de importância na medicina ${ }^{2}$.

Neste trabalho, as duas especialidades constituíram o espaço para a reflexão acerca da maneira como homens e mulheres constroem seu discurso especializado, como uma de suas formas de atuar no mundo. Partiu-se da premissa de que uma teia de significados permeia as práticas e o trabalho médico e de que as conexões estabelecidas entre os elementos processuais de construção/disseminação social destes significados constituem-se mutuamente o tempo todo.

As relações com o mundo são sempre interpretadas, e isso inclui o olhar que se pretende literalmente biomédico e, portanto, científico, pois conectado à "verdade" que os corpos ocultam. A perspectiva desse olhar, entretanto, é sempre parcial, localizada e comprometida com a posição que se ocupa neste mundo ${ }^{3}$.

As relações que os obstetras/ginecologistas observados e ouvidos estabelecem com o mundo estão marcadas por uma presença não neutra, compromissada e contextualizada, na qual está incluído o processo histórico de constituição da medicina e, também, os significados culturais compartilhados, atribuídos aos profissionais médicos e subliminarmente incorporados por eles. E, sem dúvida, um significado importante se relaciona à reprodução da vida.

O texto a seguir parte dos depoimentos de residentes em Obstetrícia/Ginecologia e objetiva apresentar e discutir dois eixos que se evidenciaram como bases da construção do discurso especializado: as características do médico obstetra/ginecologista e as marcas do normal e do estranho na experiência da prática assistencial.

\section{FONTES E MÉTODOS}

Foi realizado um estudo de caso institucional ${ }^{4}$ com sete dos oito residentes dos serviços de Obstetrícia e Ginecologia do Instituto Fernandes Figueira (IFF), Fundação Oswaldo Cruz (Fiocruz), que concluíram a residência médica em janeiro de 2004 após dois anos de formação. O oitavo residente não pôde participar por se encontrar de licença médica. A idade dos entrevistados variou entre 25 e 27 anos, sendo cinco deles oriundos de universidades públicas federal e estadual, e dois de universidades particulares.

Seguindo a proposição de Stengers ${ }^{5}$ num pequeno ensaio sobre ciência e gênero, não se pretendeu lançar mão de teorias e conceitos acerca da temática de gênero, mas, de forma geral, encarar as características dadas à formação, independentemente de estas partirem de residentes mulheres ou homens. O objetivo foi captar como percebiam as particularidades da especialidade escolhida, considerando-os como compartilhando a visão predominante, na cultura ocidental da atualidade, acerca da Obstetrícia/Ginecologia. A temática da distinção de gênero só foi incorporada ao ter sido utilizada pelos residentes para caracterizar a construção da especialidade, não constituindo, portanto, objeto deste estudo.

O IFF é um hospital público que apresenta um processo de complexificação crescente. Ele se classifica como terciário no atendimento à criança, com serviços especializados e de referência que incluem uma UTI neonatal e outra para crianças maiores, e secundário no atendimento à mulher. Os casos atendidos na Obstetrícia se caracterizam pelo alto risco fetal, devido à especificidade do hospital, e envolvem, na maioria das vezes, malformações congênitas.

A pesquisa foi operacionalizada em duas etapas: observação participante em quatro reuniões clínicas da Obstetrícia (Clube do Feto) e em quatro da Ginecologia (CIC - Confirmação de Indicação Cirúrgica), com o objetivo de recolher dados, registrados sob a forma de notas de campo, para servir de subsídio à segunda etapa: a construção de fontes orais.

O método utilizado nesta última, elaborado e validado por Cardoso $^{6}$, é composto por quatro módulos de entrevistas - contato, história de vida, entrevista temática e depoimento livre -, articulando três tipos de memória: individual, coletiva e histórica. Como as bonecas russas, Matrióchka, que se encaixam umas dentro das outras, os depoimentos orais contêm, além das histórias pessoais dos entrevistados, informações que, para além de individuais, falam sobre tradições e valores presentes nas especialidades, na medicina e mais amplamente na ciência, que podem estar sendo reproduzidos por eles. Os depoimentos foram 
gravados num período de quatro meses, com duração média de três horas e vinte minutos por pessoa e posteriormente transcritos. Os entrevistados foram nomeados por siglas para preservar sua identidade.

Após uma codificação qualitativa com o intuito de identificar os temas de interesse, fez-se uma análise semiótica do material, observando-se os seguintes elementos: coerência textual, competência textual e intertextual, estruturas superficiais e profundas do texto (como os significados são colocados em discurso) e o processo de "discursivização", que compreende a instituição de personagens ("actorialização"), os efeitos de tempo e espaço ("temporalização e espacialização") e o surgimento de elementos abstratos ("tematização") e concretos ("figurativização" $)^{7}$. A pesquisa foi aprovada pelo Comitê de Ética em Pesquisa do IFF, sob o parecer $n^{\circ} 054 / 03$, de 4 de dezembro de 2003, e recebeu suporte financeiro da Capes.

Cabe ressaltar que os resultados que seguem, mostrados por meio da exemplificação dos tópicos verbalizados via frases proferidas pelos residentes, refletindo a posição geral, vinculam-se à opção de realizar um estudo de caso institucional e uma pesquisa de cunho estratégico. Portanto, as observações generalizantes foram formuladas por interpretação e inferência, considerando a ingerência, no discurso especializado em construção, das características impostas pela complexidade da demanda de uma unidade hospitalar, com as características do IFF/Fiocruz. Desse modo, o estudo apresentado se configura como uma contribuição no sentido de fornecer subsídios a futuras análises em unidades diferentes daquela aqui focalizada, de modo a favorecer a incorporação de uma dimensão comparativa. A multiplicação de análises desse tipo, sem dúvida, seria fundamental no esforço de delimitar as características da personalidade e os estereótipos que urdem a trama da construção do discurso especializado e, assim, ajudar na formulação de estratégias pedagógicas aplicadas à formação e à educação médicas nas áreas básicas da medicina, como a Obstetrícia e Ginecologia.

\section{RESULTADOS}

No que diz respeito ao eixo categorizado como "médicos residentes: obstetras/ginecologistas em construção", a análise dos depoimentos explicitou a percepção do médico obstetra/ginecologista como essencialmente cirúrgico, apesar das exigências de habilidades clínicas. As motivações aparecem precocemente e estreitamente associadas a características de personalidade. Não são registradas pelos residentes diferenças significativas entre mulheres e homens no tocante ao aprimoramento do raciocínio clínico, no pro- cesso de construção do discurso especializado e, sim, na forma de funcionamento dos grupos da Obstetrícia e da Ginecologia.

Nos depoimentos, o perfil do médico que escolhe Obstetrícia/Ginecologia é definido como o de pessoas voltadas para a resolução de problemas, impacientes e práticas, com pouco interesse por aspectos profundos e abstratos da vida, e com um conteúdo de agressividade comum às outras especialidades cirúrgicas, permitindo a realização de atos invasivos nas pacientes.

Dentre os sete depoentes, apenas um se identifica como clíni$\mathrm{co}$, priorizando atitudes de delicadeza e pudor no atendimento à mulher, por lidar com partes do corpo que envolvem sentimentos de vergonha: “Eu acho que é uma profissão que exige um pouco mais de cuidado da gente, e a gente acaba tendo essa preocupação de cuidado com o corpo da paciente" (S5). Os demais se percebem mais cirúrgicos.

O treinamento em Obstetrícia/Ginecologia não é comum aos que escolhem residência em cirurgia, entretanto eles identificam as especialidades como cirúrgicas e a si mesmos como apresentando características comuns àquele grupo, além de uma afinidade com esse tipo de procedimento. Conforme comentam S3 e S4: "As pessoas que fazem GO têm um perfil de mais objetividade, essa coisa da parte cirúrgica; [...] pessoas com características mais agressivas, [que gostam] de resolver imediatamente [e] não ter que lidar com coisas crônicas [...] (S3); “Tem que gostar mais da área cirúrgica [senão] não dá para fazer Ginecologia e Obstetrícia" (S4).

A habilidade manual é valorizada, sendo importante a contabilização do número de cirurgias praticadas durante a residência, um dos fatores apontados como decisivos na escolha da instituição. No entanto, no IFF, como o volume de cirurgias é baixo comparado com outros hospitais, os residentes ressaltam a falta de oportunidade de praticar certos procedimentos conhecidos apenas teoricamente. Nesse sentido, o dito por um deles reflete a posição/visão consensual: "A gente sabe os tempos da cirurgia, sabe a teoria, mas não tem mão, não tem prática para encarar aquilo" (S2).

Segundo os entrevistados, algumas áreas cirúrgicas são ainda quase vetadas para as mulheres, como a ortopedia e a neurocirurgia, sendo argumentado por todos, mulheres e homens, que isso se deve a uma questão de força física, no caso da Ortopedia, ou de resistência para permanecer muitas horas em pé, no caso da Neurocirurgia, cujos procedimentos tendem a ser mais longos.

Os entrevistados apontam diferenças no funcionamento dos dois serviços, considerando a Obstetrícia uma representação de um modelo feminino, e a Ginecologia, de um modelo masculino. A Obstetrícia é vista como mais acolhedora, familiar, que respeita a inexperiência profissional porque tem no seu funcionamen- 
to uma metáfora da própria gestação, tal como mostra a frase: "O relacionamento na Obstetrícia, eu acho que é mais acolhedor. A gente se sente melhor na maternidade" (S1). A Ginecologia, por sua vez, é vista como mais fria, tensa, "o contato é mais impesso$\mathrm{al}^{\prime \prime}$ (S7). Todos apontaram que cada médico em formação existe não como indivíduo, mas como parte de um grupo transitório que não deixa marcas pessoais na equipe. Conforme afirma S6: "A residência é a transição entre a proteção e ser jogado no mundo".

Os residentes registram que as pacientes tendem a escolher médica mulher para a clínica ou parto normal e o homem para a cirurgia. Nas palavras de um dos entrevistados, sintetizando o geral: "[Para a] cirurgia, acha-se que o homem tem mais experiência, mais 'sangue-frio'. O homem, nessas horas de estresse, numa coisa inesperada, às vezes se comporta melhor. Mas [não é] questão de habilidade, é [o] comportamento frente a uma situação adversa" (S7).

Os depoentes salientam a necessidade de se entender a mulher como uma característica importante do perfil do médico que escolhe Obstetrícia/Ginecologia e a explicação de por que isso não acontece é simbolizada pelas palavras de S4: "Lidar com mulher é mais complicado mesmo, principalmente gestante".

A imprevisibilidade, conforme verbalizado pelos residentes, mostra-se de forma diferenciada nas duas áreas, da mesma forma que os profissionais; alguns preferem a Obstetrícia por seu caráter emergencial, enquanto outros preferem a Ginecologia por não envolver a demanda e a sobrecarga da primeira, que "lida com duas vidas nas mãos" (S5), e a cobrança que surge com um desfecho inesperado por lidar mais com prevenção do que com doença.

O que se categorizou como "o normal e o estranho", um dos temas destacados nas entrevistas, diz respeito ao padrão de normalidade que envolve tanto a Obstetrícia quanto a Ginecologia, caracterizando-as, segundo os depoentes, como especialidades associadas mais à vida do que à doença e, implicitamente, à morte. Todos concordam com o dito por dois deles:

A Obstetrícia é bonita, é uma coisa que não é uma doença em geral. Eu acho que tem a parte complicada, mas em $90 \%$ das vezes é uma coisa que dá certo, não é uma doença, é vida. E a Ginecologia também. Até tem o câncer, o lado mais pesado, mais crônico. Mas tem muita coisa que você consegue resolver bem, problemas pequenos (S3) e As pessoas que fazem Ginecologia/Obstetrícia em geral não gostam muito de pacientes críticos, pacientes terminais (S1).
Na Obstetrícia, segundo eles, esse padrão mostra-se de forma acentuada no desejo de que a experiência de dar à luz uma criança seja exclusivamente agradável, permeada por fantasias pessoais e sociais de felicidade, beleza e perfeição, conforme comenta um dos residentes, respaldando a visão geral:

Ser mãe é de uma hora para outra ter o "bebê Johnson" nos seus braços. Eu acho que tem a ver com o caminho cultural que a sociedade como um todo está tomando. As coisas têm que ser perfeitas; a dor não está dentro da perfeição. [A] Obstetrícia, [entre as] especialidades, é a pior em termos de cobrança, porque Obstetrícia não [lida com] doença, é um momento feliz (S2).

O primeiro contato com casos raros, mormente de malformações congênitas, angustia os residentes, que têm que aprender a lidar com o inevitável sentimento de choque. A posição a seguir reverbera a sensação geral: "Essa foi a parte que mais me incomodou: ver as aberrações, uma coisa que é genética ou não, mas é uma coisa totalmente inexplicável. Às vezes, você tem que estar ali e resolver, mas você não vai resolver" (S3).

No referente às novas tecnologias de fertilização, alguns enxergam um novo campo em expansão, mas outros são reticentes. Esses veem as novas conquistas, mas questionam o rumo que o assunto está tomando, no sentido de estimular o "mover montanhas fazendo tratamentos" (S1) e gerar expectativas de solução rápida e simples.

Segundo os depoentes, a alta taxa de cesáreas deve-se também a outros fatores, além daquele vinculado à perfeição: a) maior racionalização do tempo do médico, de forma que a espera que precede o trabalho de parto deixa de interferir na sua rotina de trabalho; b) intenção da paciente de se submeter à esterilização cirúrgica durante a cesárea; c) controvérsias com relação a formas de pagamento do procedimento e do não pagamento da anestesia peridural em partos vaginais pelo SUS; d) e até questões de segurança bastante atuais, que levam o médico a evitar determinados lugares em horas de pouco movimento.

\section{DISCUSSÃO}

Conforme comentado por Martins ${ }^{8}$, Manente define o campo cirúrgico como intervencionista, de duração limitada no tempo, com procedimentos padronizados, enquanto o campo clínico é conceituado como menos padronizado, abarcando práticas mais flexíveis, em que o paciente é mais ativo, e a relação com o médico tende a acontecer durante um período de tempo maior.

Essa descrição coincide em grande parte com o perfil dos cirurgiões que aparecem em estudos sobre tipificação psicológica de diversas especialidades ${ }^{8}$. Resultados semelhantes foram en- 
contrados por Bellodi ${ }^{9}$ em pesquisa com 60 residentes do primeiro e segundo anos de programas de residência em Cirurgia e Clínica Médica ao investigar o peso dos estereótipos vinculados às figuras de clínico e cirurgião na escolha da especialidade. Porém, tanto a Obstetrícia quanto a Ginecologia têm uma atividade clínica importante, que exige do médico habilidades específicas.

Desde a faculdade é possível perceber, como dito pelos entrevistados, o delineamento das escolhas: quem tem perfil clínico e cirúrgico. Para eles, as tendências emergem de modo flagrante. Segundo Bellodi ${ }^{9}$, tal escolha envolve não apenas características pessoais, mas é também influenciada por estereótipos profissionais compartilhados socialmente. Segundo a autora verificou em sua pesquisa, os cirurgiões tendem a maior estabilidade em suas escolhas feitas ainda na faculdade, se comparados aos que optam por clínica geral ${ }^{10}$.

Seis dos entrevistados se percebem mais cirúrgicos, mas reconhecem a necessidade de desenvolver características ligadas à clínica, como paciência, disponibilidade para ouvir e capacidade educativa, por envolver procedimentos de cunho preventivo. Também demonstram "interpretar" essas características. Sabem-nas importantes, por isso mostram preocupação em exercitá-las por meio de comportamentos, evitando, por exemplo, palavras estigmatizantes, como "esterilidade", substituindo-a por infertilidade primária ou secundária, ou esforçando-se para mostrar maior interesse na expressão subjetiva do sofrimento da paciente. Todavia, ambas as estratégias configuram-se mais como uma formalidade aprendida como correta do que algo espontâneo e entendido como intrínseco ao encontro clínico entre médico e paciente.

A antropóloga Joan Cassell ${ }^{11}$, em seus estudos com cirurgiões em geral, descreve a cirurgia como uma especialidade marcial, invasiva, estereotipada como masculina, e seus praticantes como temperamentais, com potencial de comando, competitivos, apreciadores de desafios e voltados à ação. Embora a autora exclua os obstetras/ginecologistas, por seguirem um programa de formação independente, os resultados se assemelham aos encontrados nas entrevistas com os residentes do IFF.

Ainda segundo Cassell ${ }^{11}$, a atividade cirúrgica envolve os corpos das pacientes e dos profissionais, em especial o do médico, cuja habilidade é desenvolvida primordialmente na repetição constante dos procedimentos. Existe uma coreografia corporal no ritual cirúrgico, que envolve desde a preparação dos profissionais com a vestimenta e a assepsia até o seu posicionamento na sala de cirurgia. As próprias condições da cirurgia, como o tempo gasto no procedimento, que faz o médico ficar horas sem comer, sem descansar ou mesmo dormir, moldam o corpo do profissional, tornando-o capaz de suportá-las com menos esforço.

No caso da Obstetrícia/Ginecologia, os procedimentos cirúrgicos não são longos, ponto importante para vários depoentes, que não se incomodam em passar o dia operando, mas que se consideram muito impacientes para despender mais do que quatro ou cinco horas numa mesma intervenção.

A espécie de veto existente para as mulheres em algumas especialidades parece associada não apenas a estereótipos culturais, que estabelecem diferenças entre homens e mulheres, mas a valores profissionais/especializados inculcados precocemente, ou, como afirma Bellodi, "à tradição dos antigos físicos (especialmente quanto à valorização da mente) e dos cirurgiões barbeiros (associados a um menor conhecimento e à realização de procedimentos arriscados na história da medicina)"12 (p. 201). Aliam-se a esses estereótipos aqueles introjetados e corporificados desde cedo, que identificam a mulher como mais frágil física e emocionalmente que o homem e, portanto, mais suscetível a perder o controle ${ }^{11}$.

A análise preliminar deixou claro que, para os depoentes, não há diferenças no modo de raciocinar clinicamente entre médicos e médicas obstetras/ginecologistas; as características prevalentes em ambos os sexos são o caráter informativo e o não julgamento. Todavia, ao se aprofundar a análise, evidenciam-se diferenças entre homens e mulheres em geral, implicitamente presentes num aparente olhar o mundo da medicina que seria comum a todos.

A mulher é revestida de características como delicadeza, capacidade de escuta, percepção aguçada para captar sutilezas da paciente que extrapolam o campo fisiológico e adentram o psicológico, facilitando a relação; o homem é apontado como mais racional, menos sensível, voltado à ação mais do que às palavras. Porém, tais assunções frequentemente se fazem acompanhar de comentários sobre o médico homem ser capaz de entender melhor a paciente porque, ao não vivenciar os mesmos processos que ela, é capaz de valorizar o que ela sente. Em contrapartida, a mulher, por passar pelos mesmos fenômenos, como menstruação e cólicas, por exemplo, não pondera tanto o que individualmente pode ser difícil ou desagradável.

Percepções semelhantes são registradas por Cassell ${ }^{11}$ : seus entrevistados não apontam diferenças significativas entre homens e mulheres cirurgiões, mas identificam características em ambos que estabelecem padrões diferentes, contrastando o cuidado à paciente com o cuidado apenas ao corpo da paciente. São características vinculadas à forma de cuidar, como afeto, preocupação e abertura à ex- 
periência, que estimulam o desenvolvimento do outro, estejam elas presentes em homens ou mulheres.

Apesar de ter o interior do seu corpo devidamente "mapeado" por ambas as especialidades, tanto médicos quanto médicas percebem, no momento do atendimento, um hiato entre eles e a mulher, cujo corpo foi mapeado, que não é transposto, sendo necessário lançar mão de rótulos com os quais se relacionam. Por exemplo, as pacientes geralmente são classificadas como "complicadas", "simples", "dramáticas", "guerreiras"...

É importante salientar que rótulos estão enraizados tanto nos médicos quanto nas pacientes não só em termos racionais e conscientes, mas impressos no corpo, que reage em correspondência às suas percepções, acalmando-se ou se atemorizando diante de comportamentos que seguem padrões preestabelecidos; assim, a paciente também se relaciona com estereótipos de médicos, esperando deles atitudes de acordo com suas expectativas.

O ingresso da mulher na Obstetrícia/Ginecologia, após as parteiras, se por um lado significou uma exigência de masculinização da mulher por ingressar numa profissão até então exclusivamente masculina, por outro, mostrou-se adequada, por serem mulheres tratando mulheres, diminuindo o desconforto pelos tabus relativos ao contato com o corpo ${ }^{1}$. Hoje, a crescente presença de mulheres na medicina provoca mudanças no quadro das universidades, dando sinais de que está se tornando uma profissão igualmente de homens e mulheres, conforme dados do Cremesp de 2005, que mostram que na faixa de 21 a 24 anos de idade $57 \%$ são médicas.

No que se refere ao segundo eixo temático, tornado evidente pela análise semiótica, é preciso salientar que o IFF, por ser um hospital especializado, com um padrão de intercorrências neonatais graves, apresenta aos novos médicos uma residência em Obstetrícia/Ginecologia diferente daquela de um hospital geral. Desde o começo, o contato com tal tipo de casos exacerba a insegurança decorrente da transição aluno/profissional e requer dos residentes estratégias para lidar com situações consideradas difíceis não apenas pela escassa experiência, mas pelo forte apelo emocional que escapa ao controle.

A sociedade ocidental moderna se encontra ancorada no modelo de normalidade, associada a beleza, perfeição e produtividade. $\mathrm{O}$ que não se encaixa nesses padrões apresenta-se como estranho, diferente, tocando na estranheza e na imperfeição de cada $\mathrm{um}^{13}$.

Para Gambini ${ }^{14}$, a partir da perspectiva de Jung ${ }^{15}$, o estranho aparece como sombra, obscuridade e, justamente por ser desconhecido, serve como espelho. Mas se é espelho, mostra o que está diante dele, logo, aspectos inconscientes daquele que vê, suas imperfeições, limitações e também qualidades, que tiveram seu acesso à consciência bloqueado e se encontram não explicitados por representarem uma ameaça.

De acordo com Canguilhem ${ }^{16}$, normal e anormal não são da mesma natureza: o normal refere-se à capacidade de adaptação às flutuações do meio em que se vive; o anormal implica uma norma diferente e não a ausência de norma. Ser sadio significa ser flexível, ser capaz de criar normas diferentes para enfrentar situações novas. A situação de doença reduz essa flexibilidade, e o que a caracteriza é uma perda da capacidade normativa, uma diminuição dos limites de tolerância às instabilidades do meio.

O estado patológico é um tipo de normal, diferente, porém, do estado fisiológico. O limite entre um e outro é muito impreciso quando se fala de pessoas diferentes, mas fácil de ser percebido em se tratando da mesma pessoa. A cura possibilita não uma volta às condições anteriores à doença, mas a obtenção de uma nova norma de vida, que pode, inclusive, ser mais adequada ${ }^{16}$.

O nascimento do "bebê perfeito" corresponde em outro aspecto ao modelo de linha de montagem de produção de bens, onde o produto do nascimento é o bebê, e a mãe assume uma posição secundária nesse processo. Esse bebê-produto é possível devido a um aparato tecnológico de monitoramento capaz de "garantir sua qualidade"17.

A Obstetrícia do IFF está intrinsecamente ligada ao estranho, pelo tipo de clientela que atende. Dar à luz uma criança malformada, "anormal", significa enfrentar a personificação da estranheza, do monstruoso, que existe na fantasia de cada pessoa e não alguém que pode estar inserido em uma norma vital diferente. Envolve sentimentos de frustração e impotência por parte dos médicos, relacionados ao estabelecimento do diagnóstico e das possibilidades de cura.

Alguns depoentes a negam, mas outros priorizam a compensação advinda do estudo de casos "raros e graves". Uma identificação com a figura tradicional de mulher/mãe acontece, dando margem a reflexões sobre as angústias relacionadas à possibilidade de gerar uma criança malformada, algo que está além do seu conhecimento e controle.

Por outro lado, o estranho não necessariamente designa uma anomalia, isto é, uma variação que diferencia um indivíduo de outros de sua espécie, seja ela apenas diversidade ou patológica, como nas deformidades restritivas das normas vitais ${ }^{16}$; ela pode significar o contato com alguém que segue valores e visões de mundo diferentes, entre as quais a mulher homossexual e aquela que lida com seu corpo de forma diversa da do médico ou da equipe de saúde. 
Em medicina da reprodução, o que se pode chamar de "desejo de ter filhos" é entendido, numa acepção muito próxima do senso comum, como algo consciente e equivalente à vontade, que move os indivíduos em seus atos e decisões. Todavia, mais do que desejada, essa criança torna-se necessária, pois sem ela a família e a mulher se tornam incapazes, fracassadas, o que pode acarretar sentimentos de vergonha. A necessidade é a forma de criar uma demanda à medicina, reforçand o o mito da solução do problema por sua ação reguladora ${ }^{18}$.

A fertilidade é tida como "normal" e socialmente desejável, enquanto a infertilidade é vista como anormalidade, como estranho, devendo ser medicalizada, numa tentativa de adequação à norma muito mais em termos sociais do que biológicos, visto que a reprodução assistida não "cura" a infertilidade, apenas a contorna $^{18}$.

No IFF, os procedimentos de reprodução assistida não são realizados, e as opiniões dos depoentes variam com relação a eles. Alguns se mostram bastante favoráveis, por caracterizarem uma possibilidade de "solução" para as mulheres que não podem ter filhos, considerando esse desejo como essencial e unânime entre mulheres e homens.

A dificuldade de discutir aspectos relacionados ao aborto, uma das facetas do estranho, ou até de realizá-lo em casos autorizados pela lei, é trazida por todos os entrevistados. Surgem posicionamentos que diferenciam a opinião do profissional e a opinião da pessoa do médico. Quando é o profissional que fala, os argumentos a favor ou contra são claros e objetivos; quando é a pessoa, o mais comum é não ter uma opinião bem definida. Algumas situações são justificadas, como no caso de malformações incompatíveis com a vida, mas outras não, como no caso de bebês sadios.

A possibilidade de escolha pela mulher não aparece como alternativa possível, a não ser nos casos com indicação médica. Além dos elementos morais, religiosos, legais e médicos, um dos aspectos que pode estar envolvido se relaciona à ideia do aborto como negação do aspecto nutriz e cuidador da mulher e da família. Aceitá-lo significaria questionar esses conceitos.

O aconselhamento genético, com suas técnicas, é uma forma de lidar com o estranho, com o que é considerado anormal. É visto pelos entrevistados, por um lado, como importante fonte de informação sobre e para a paciente, apesar dos riscos inerentes a determinados procedimentos, como a amniocentese. No entanto, nenhuma referência é feita aos perigos de determinismos reducionistas ou de transformar os riscos genéticos em fetiche ou dogma ${ }^{19}$. Eles questionam o encaminhamento de determinadas informações obtidas, uma vez que soluções nem sempre são possíveis ou porque não há o que fazer para modificar o quadro e o prognóstico, ou pela impossibilidade dos abortos terapêuticos.

Uma das dificuldades do homem é não conseguir se deparar com o que não pode controlar, seja no nível técnico, simbólico ou teórico. A cultura se apresenta como um código estruturante de lei e ordem, e tudo o que aparece como insólito, estranho, fora das normas, interposto entre algo próximo e conhecido e algo que é distante e desconhecido representa uma fonte de perigo. A doença é temida por se caracterizar como um estado intermediário entre vida e morte ${ }^{20}$.

Para os residentes, o padrão de normalidade está relacionado ao número crescente de cesáreas praticadas, por opção tanto do profissional quanto da paciente, com vistas a diminuir os riscos e tornar o procedimento mais controlável pelos médicos. Essa postura é coerente com uma atuação mais defensiva na medicina, além de permitir a eliminação da dor, pois, conforme emergiu da análise, a dor não seria condizente com a perfeição almejada.

A cesárea é "um procedimento cirúrgico originalmente desenvolvido para salvar a vida da mãe e/ou da criança, quando ocorrem complicações durante a gravidez ou o parto" (p. $1.612)^{21}$ e, como tal, não está isenta de riscos. Dados do Ministério da Saúde apontam um crescimento desse tipo de parto, que chega a 41\% em 2003, em termos nacionais, com diferenças entre municípios, estados, áreas urbanas e rurais ${ }^{22}$. $\mathrm{O}$ índice máximo considerado adequado pela Organização Mundial de Saúde (OMS), segundo dados de 1996, é de 15\%.

Algumas pesquisas evocam uma correlação entre o aumento de técnicas de monitoramento fetal, que permitem o diagnóstico de sofrimento ou de qualquer outra anormalidade, e a crescente indicação precoce do parto cesáreo, em nome, muitas vezes, da prevenção ${ }^{23}$

A análise do observado e do dito permite afirmar que essas pesquisas foram respaldadas, visto que se constatou a produção do significado "estranho", detectável por meios tecnológicos, como ponto de legitimação de um saber especializado, portanto, verdadeiro, que guia a escolha do procedimento a ser executado.

\section{CONSIDERAÇÕES FINAIS}

É no momento da residência que coexistem as dimensões de aluno e profissional na figura do residente, o que significa que eles já são responsáveis por sua prática, mas ainda são tutelados por um preceptor. Para minimizar a insegurança dessa transição, a alternativa encontrada é a maior valorização dos exames complementares em detrimento da escuta e da construção da 
história clínica a partir do relato da paciente. No IFF, por se tratar de um hospital terciário, a maioria dos casos envolve malformações fetais, o que contribui sobremaneira para acentuar essa sensação de insegurança e o distanciamento da história trazida pelas pacientes.

A escolha da Obstetrícia/Ginecologia é guiada primordialmente pela identificação dos entrevistados com as características reconhecidas como inerentes a elas, com predominância do perfil cirúrgico sobre o clínico. Também são relevantes as afinidades com o atendimento à mulher e as possibilidades de atuação que ambas oferecem.

O caráter resolutivo dessas especialidades tende a imprimir um ritmo mais acelerado nos profissionais que as escolhem no que tange ao contato com a paciente, ilusoriamente sugerindo a pouca importância a ser dada à escuta e à construção da narrativa.

A paciente, quando chega ao médico, traz sua doença tanto no corpo quanto em sua história, que inclui suas percepções sobre o seu sofrimento, os significados a ele atribuídos, sejam eles crenças, valores, juízos, além de aspectos sócio-históricos e biográficos. Cabe ao médico perguntar-lhe sobre essa história e sobre esse corpo ${ }^{24}$.

Perguntar sobre o corpo envolve tanto uma dimensão verbal, que vai ser respondida pela paciente verbal e não verbalmente, quanto outra, não verbal, em que o médico pergunta diretamente ao corpo sobre ele: o exame físico cuidadoso é a base do encontro entre o médico e a paciente, assim como também são importantes as informações fornecidas por testes ou imagens.

Implícita nesse contato do médico com o corpo do outro está uma atitude de impessoalidade que se por um lado estabelece os marcos da relação e transmite uma aceitação desse corpo e, consequentemente, da pessoa nas condições de doença em que se encontra, por outro, pode chegar a extremos de coisificação da paciente, transformando-a na doença ou no órgão doente, mas permitindo um afastamento da dor do outro.

A narrativa médica, com seus recursos linguísticos, ao ser capaz de penetrar nas construções pessoais da paciente sobre seu estado, torna-se um importante auxiliar na reordenação desse referencial, em que os aspectos relativos à doença, como os sintomas, o estigma e as dificuldades encontradas no atendimento institucional, devem ser incorporados, resultando numa nova configuração da identidade ${ }^{25}$.

Vários trabalhos discutem o valor da semiologia médica ${ }^{26} \mathrm{eo}$ papel da narrativa em medicina, especialmente na educação médica, por sua importância no processo de construção das hipóteses diagnósticas a partir do relato da paciente ${ }^{27}$. Os exames com- plementares, em especial os que fornecem imagens, interpretados não como representações do corpo, mas como o corpo real, infundem segurança nos residentes, profissionais ainda em construção de um discurso especializado, mas também os afastam da atenção sutil necessária à escuta da história da paciente, seja ela trazida verbal ou corporalmente, para a obtenção de informações que irão compor a narrativa médica. Para os entrevistados, as imagens são mais confiáveis e mais facilmente decifráveis, pois carregam o peso ilusório da objetividade do real revelado.

A grande disponibilidade de exames, fornecendo um número crescente de informações com menor esforço, pode confundir o médico e fazê-lo perder o sentido da solicitação dos mesmos: qual a real contribuição de cada um é a pergunta a ser feita. De acordo com os entrevistados, o costume é pedir muitos exames, sendo a anamnese um caminho para, dentro da história contada pela paciente, escolher o mínimo para confirmar o que se suspeita. $\mathrm{O}$ receio é de que muitos exames tragam como consequência resultados discordantes.

E na falta de sentido, o excesso torna-se escassez. Ou, recorrendo à poesia de Nando Reis, na música Relicário: “O que você está fazendo? Milhões de vasos sem nenhuma flor".

A construção da narrativa demanda um sentido, que surge pela ordenação dos eventos da vida da paciente a partir de conjecturas do médico, ancoradas por fontes diversas, entre as quais se incluem elementos subjetivos ${ }^{27}$. Apesar do afastamento dos entrevistados do desenvolvimento da competência narrativa, ela está entrelaçada à semiologia médica e, apesar do reconhecimento de sua importância, inclusive na orientação de currículos de graduação em Medicina, infelizmente, ainda é pouco enfocada na formação e no exercício da medicina em seus diversos níveis.

\section{REFERÊNCIAS}

1. Rohden F. Uma ciência da diferença: sexo e gênero na medicina da mulher. Rio de Janeiro: Editora Fiocruz; 2001.

2. Santos Filho L. História geral da medicina brasileira. São Paulo: Hucitec; Edusp; 1991.

3. Haraway DJ. Technoscience in hypertext. In. Modest_witness@second-millenium. FemaleMan ${ }^{\odot}$ _meets_OncoMou$\mathrm{se}^{\mathrm{TM}}$ : feminism and technoscience. New York: Routledge; 1997. p.125-265.

4. Yin RK. Case study research: design and methods. $3^{\text {rd }}$ ed. London: Sage Publications; 2003. (Applied social research methods series, vol. 5). 
5. Stengers I. The thousand and one sexes of science. In: Power and invention: situating science. Minnesota: The University of Minnesota Press; 1997. p.133-52.

6. Cardoso MHCA. Programa de história oral: os quatro módulos: método e prática. Hist Cad. 1986;4(1):29-35.

7. Cardoso CF. Narrativa, sentido, história. Campinas: Papirus; 1997.

8. Martins LAN. Residência médica: um estudo prospectivo sobre dificuldades na tarefa assistencial e fontes de estresse. São Paulo; 1994. Doutorado [Tese] - Universidade Federal de São Paulo.

9. Bellodi PL. The general practitioner and the surgeon: stereotypes and medical specialties. Rev Hosp Clin Fac Med Sao Paulo. 2004;59(1):15-24.

10. Bellodi PL. Surgery or general medicine - a study of the reasons underlying the choice of medical specialty. São Paulo Med J. 2004; 122(3):81-86.

11. Cassell J. The woman in the surgeon's body. Cambridge, Massachusetts: Harvard University Press; 2000.

12. Bellodi PL. O clínico e o cirurgião. Estereótipos, personalidades e escolha da especialidade médica. São Paulo: Casa do Psicólogo; 2003.

13. Amaral LA. Corpo desviante/olhar perplexo. Psicol USP. 1994; 5(1/2):245-268.

14. Gambini R. Espelho índio. A formação da alma brasileira. São Paulo: Axis Mundi / Terceiro Nome; 2000.

15. Jung CG. O homem e seus símbolos. 14ª ed. Rio de Janeiro: Nova Fronteira; 1996.

16. Canguilhem G. O normal e o patológico. 5 $5^{\underline{a}}$ ed. Rio de Janeiro: Forense Universitária; 2002.

17. Dumit J, Davis-Floyd R. Introduction. Cyborg babies. Children of the third millennium. In: Cyborg babies. From techno-sex to techno-tots. New York: Routledge; 1998. p.1-18.

18. Corrêa MV. Novas tecnologias reprodutivas. Limites da biologia ou biologia sem limites? Rio de Janeiro: EdUerj; 2001.

19. Cardoso MHCA, Castiel LD. Saúde coletiva, nova genética e a eugenia de mercado. Cad Saúde Pública. 2003;19(2):653-662.

20. Rodrigues JC. Tabu da morte. Rio de Janeiro: Achiamé; 1983.
21. Barbosa GP, Giffin K, Angulo-Tuesta A, Gama AS, Chor D, D’Orsi E, et al. Parto cesáreo: quem o deseja? Em quais circunstâncias? Cad Saúde Pública. 2003;19(6):1611-1620.

22. Brasil. Ministério da Saúde. Departamento de Informação e Informática do SUS. Sistema de Informações de Nascidos Vivos. [acesso em 05 out. 2006]; Disponível em: http: / / www.datasus.gov.br

23. Petchesky RP. Fetal images. In: Lancaster RN, Di Leonardo M, (eds). The gender sexuality reader. New York: Routledge; 1997. p.134-150.

24. Hunter KM. Doctor's stories. The narrative structure of medical knowledge. Princeton, New Jersey: Princeton University Press; 1991.

25. Castiel LD. Moléculas, moléstias, metáforas: o senso dos humores. São Paulo: Unimarco; 1996.

Santos JB, Pires LL, Silva AE, Castro CN. Reflexões sobre o

26. ensino da semiologia médica. Rev Bras Educ Med. 2003;27(2):147-152.

Grossman E, Cardoso MHCA. As narrativas em medicina:

27. contribuições à prática clínica e ao ensino médico. Rev Bras Educ Med. 2006;30(1):6 -14.

\section{CONTRIBUIÇÃO DOS AUTORES}

Ana Cristina B. Gilbert contribuiu com a coleta e a análise dos dados e a redação do artigo.

Maria Helena C de Almeida Cardoso colaborou na análise dos dados, na concepção e na redação.

Susana M. Wuillaume e Monica de Paula Jung colaboraram na pesquisa bibliográfica, na redação e revisão do artigo.

\section{CONFLITO DE INTERESSES}

Declarou não haver.

\section{ENDEREÇO PARA CORRESPONDÊNCIA}

Ana Cristina Bohrer Gilbert

Rua Ataulpho Coutinho, 200 - bloco 3 - apto. 802

Barra da Tijuca - Rio de Janeiro - RJ

CEP: 22793-520

E-mail: ana.gilbert@terra.com.br 